\title{
Quantitative estimation of the surface carbohydrates on the infection structures of rust fungi with enzymes and lectins
}

\author{
Kurt Mendgen, Martina Lange, and Karin Bretschneider \\ Universität Konstanz, Fakultät für Biologie, Lehrstuhl Phytopathologie, D-7750 Konstanz, Federal Republic of Germany
}

\begin{abstract}
Lectins of Triticum vulgaris (WGA), Concanavalia ensiformis (ConA), Phaseolus vulgaris (PHA), Lotus tetragonolobus (LTA), Arachis hypogaea (PNA), Ricinus communis (RCA I), Griffonia simplicifolia (GSA II) and the enzymes endo- $(1 \rightarrow 3)-\beta$-D-glucanase, exo- $(1 \rightarrow 3)-\beta$-Dglucanase and laminarinase were tested for binding to the infection structures of Puccinia coronata and Uromyces appendiculatus. The enzymes and lectins were labeled with fluorescein, and the fluorescence was measured with a microscope photometer. GSA II and ConA bound to all parts of the two rust fungi to a certain extent. The germ tubes of $P$. coronata bound at least two times more WGA than did the germ tubes of $U$. appendiculatus. The appressoria of both rust fungi additionally bound exo- $(1 \rightarrow 3)$ - $\beta$-glucanase, endo$(1 \rightarrow 3)$ - $\beta$-glucanase and laminarinase. The substomatal vesicle and the infection hypha of both rust fungi mainly bound the glucanases. Furthermore, the substomatal vesicle of $U$. appendiculatus bound PHA. No obvious binding with LTA, RCA I and PNA was observed. Binding generally could be inhibited by appropriate haptens. Binding to uredospores generally appeared unspecific. The results indicate that the germ tubes have chitin on their outer surfaces, the appressoria chitin and glucans and the substomatal vesicles and infection hyphae mainly glucans. Compared to $P$. coronata, $U$. appendiculatus has more terminal linked glucose residues or the glucan has more $(1 \rightarrow 6)$ - $\beta$-linkages. Also, $U$. appendiculatus has $\mathrm{N}$-acetylgalactosamine or a similar sugar on the surface of the substomatal vesicle.
\end{abstract}

Key words: Bean rust - Uromyces appendiculatus - Crown rust - Puccinia coronata - Phaseolus vulgaris - Avena sativa - Lectins - Surface carbohydrates

Uredospore germ tubes of Puccinia graminis tritici and Uromyces phaseoli (= appendiculatus) contain proteins, lipids and the sugars glucose, mannose, some galactose and $\mathrm{N}$-acetylglucosamine (Joppien et al. 1972; Trocha et al. 1974; Trocha and Daly 1974). The carbohydrate polymers consist of $(1 \rightarrow 3)$ glucose and mannose, highly branched by

Offprint requests to: $\mathrm{K}$. Mendgen

Abbreviations. ConA, Concanavalia ensiformis agglutinin; FITC, fluorescein isothiocyanate; GSA II, Griffonia simplicifolia agglutinin II; LTA, Lotus tetragonolobus agglutinin; PBS, phosphate buffered saline; PNA, Peanut agglutinin; RCA I, Ricinus communis agglutinin I, PHA, Phaseolus vulgaris agglutinin; WGA, Wheat germ agglutinin
$(1 \rightarrow 6)$ bonds. The polymeric amino sugar of the germ tube wall is $\mathrm{N}$-acetylglucosamine, probably as chitin (Joppien et al. 1972). Glucosamine may exist as part of the chitin polymer (Trocha and Daly 1974). Using relatively mild conditions, Kim et al. (1982) moreover detected fucose, rhamnose and ribose in uredosporelings of $P$. graminis tritici.

Which of these carbohydrates are on the surface of germ tubes or other infection structures of pathogenic fungi is of special interest since these structures contact the host and might influence the host-parasite interaction (Mirelman et al. 1975; Albersheim and Anderson-Prouty 1975).

Rust fungi are especially suited for investigating surface carbohydrates since they have a series of infection structures. During their development, an appressorium develops at the tip of the germ tube. This appressorium differentiates an infection peg at its bottom which pushes its way through the stoma. Then, a substomatal vesicle evolves, the infection hypha emerges, and host cell penetration with haustorium formation is initiated by the development of a haustorial mother cell. The surface carbohydrates of these infection structures with their different tasks during host infection might be of special importance. We used two rust fungi of different genera, Puccinia coronata var, avenae, the oat crown rust fungus, and Uromyces appendiculatus var. appendiculatus, the bean rust fungus.

The estimation of surface carbohydrates has a number of technical problems, since chemical treatment of hyphae is not restricted to their surfaces. Functional entities may be degraded and such methods are not selective enough (Wessels and Sietsma 1981). Therefore we used FITC labeled lectins to study the surface carbohydrates. This method has been used successfully with a number of phytopathogenic fungi (Pistole 1981). To localize glucans, we used FITC labeled glucanase enzymes. To avoid subjective estimations, fluorescence intensity was measured with a microscope photometer.

\section{Material and methods}

\section{Uredospores}

Leaves of Phaseolus vulgaris L. cv. Favorit and Avena sativa L. cv. Selma were inoculated respectively with aqueous uredospores suspensions of Uromyces appendiculatus (Pers. ex Pers.) Ung. var. appendiculatus, race SWBR and Puccinia coronata Cda. var. avenae Fras \& Led., race HKR 2. The plants were incubated at high humidity overnight, then held in growth chambers at $20^{\circ} \mathrm{C}$ with a $18: 6 \mathrm{~h}$ light: dark cycle 
and 10,000 $\mathrm{lx}$ fluorescent light. 10-15 days after inoculation, the uredospores were harvested and used immediately.

\section{Membranes}

The membranes were prepared after Maheshwari et al. 1967: $6 \mathrm{ml}$ diethylether, $40 \mu \mathrm{l}$ paraffin oil, $2 \mathrm{ml}$ ethanol and $2 \mathrm{ml}$ collodium (4\%, DAB6), were mixed, poured into Petri dishes and the solvent was allowed to evaporate. The crown rust needed $80 \mu \mathrm{l}$ paraffin oil to form appressoria on the membranes (Wimmer 1984). The membranes were floated on water and spread on agar before they were evenly inoculated with fresh uredospores in a settling tower.

\section{Lectins, fluorescein isothiocyanate (FITC) labeled}

Wheat germ agglutinin (WGA): From Triticum vulgaris. From Sigma, in phosphate buffer $0.01 \mathrm{M}$, with $0.15 \mathrm{M}$ $\mathrm{NaCl}, \mathrm{pH} 7.2$ (PBS). Inhibitor: Hydrolysate of chitin, prepared after Hankin und Anagnostakis (1975). Concanavalia ensiformis agglutinin (ConA): From Sigma, in Tris buffer, $0.01 \mathrm{M}$, with $0.01 \mathrm{M} \mathrm{MgCl}_{2}, 0.01 \mathrm{M} \mathrm{CaCl}_{2}$ and $0.015 \mathrm{M}$ $\mathrm{NaCl}, \mathrm{pH} 7.2$. Inhibitor: $0.2 \mathrm{M} \alpha$-methyl-D-mannopyranoside (all sugars from Sigma). Phaseolus vulgaris agglutinin (PHA): Type VF. From Sigma, in PBS. Lotus tetragonolobus agglutinin (LTA): From Sigma, in PBS. Inhibitor: $0,2 \mathrm{M} \alpha-\mathrm{L}$ fucose. Peanut agglutinin (PNA): From Arachis hypogaea. From Sigma, in PBS. Inhibitor: $0.2 \mathrm{M} \beta$-D-galactose. Griffonia simplicifolia agglutinin II (GSA II): From Medac, Hamburg, in PBS. Inhibitor: $0.2 \mathrm{M} \mathrm{N}$-acetyl-glucosamine. Ricinus communis agglutinin I (RCA I): From Medac, Hamburg, in PBS. Inhibitor: $0.2 \mathrm{M}$ D-galactose.

\section{Enzymes}

The endo-(1- $\rightarrow 3)-\beta$-D-glucanase, from Rhizopus arrhizus QM 6789 and exo-(1 $\rightarrow 3)-\beta$-D-glucanase, from the basidiomycet QM 806 was a gift from Dr. E. T. Reese, Natick Development Center, MA, USA. The laminarinase from mollusk, 0,8 mg/ml, was from Sigma, Heidelberg, FRG. The enzymes were labeled with FITC after Nairn (1964) and Benjaminson (1969).

To inhibit the enzyme binding, the samples were incubated with a mixture of the enzyme and a solution of laminarin, $180 \mathrm{~g} / 1$ (Serva, Heidelberg, FRG), incubated for 1 min and washed with PBS repeatedly.

\section{Incubation and observation}

The uredospores were allowed to germinate and to form infection structures on the membranes for $48 \mathrm{~h}$ at $20^{\circ} \mathrm{C}$ in the dark. A drop of buffer with the lectin, $0.1 \mathrm{mg} / \mathrm{mil}$, or enzyme, $0.9 \mathrm{mg} / \mathrm{ml}$ or of the inhibitory sugar together with the lectin or enzyme was placed on the membrane for $30 \mathrm{~min}$. After incubation, the membrane was washed with buffer repeatedly, covered with immersion oil and observed with a Leitz Ortholux II microscope equipped with a $100 \mathrm{~W}$ mercury lamp for epifluorescence and an I 2 fluorescence filter set (BP 450-490, RKP 510, LP 515). For photography, Ilford HP 5 film was developed in Emofin.

\section{Microscope photometry}

The Leitz MPV 2 microscope photometer with an automatic shutter system allowing measuring times of $0.25 \mathrm{~s}$ was used.

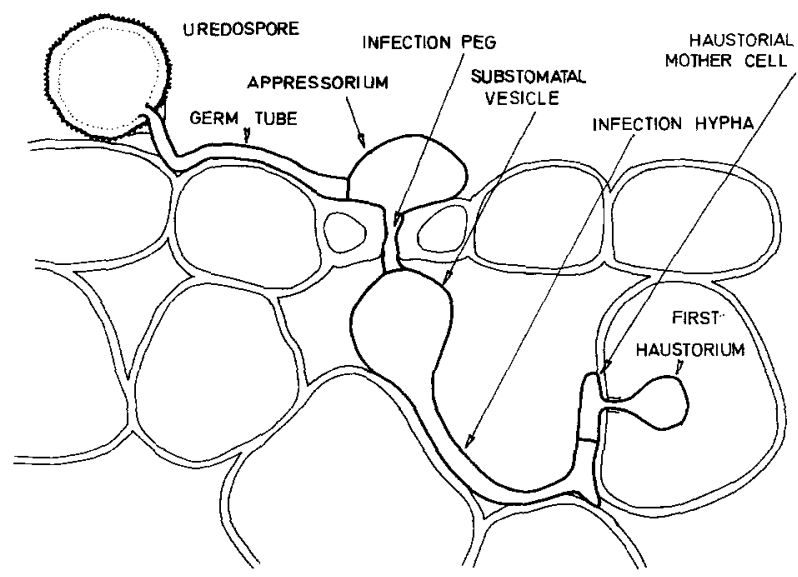

Fig. 1. Diagrammatic representation of a cross section showing the infection structures originating from a uredospore on the leaf surface

The instrument was standardized to give a reading of 100 units by using a measuring diaphragm of $4 \times 2.5 \mu \mathrm{m}$ and a solution of $25 \mu \mathrm{M}$ fluorescein diacetate, prepared after Jongsma et al. (1971), in a chamber of $0.1 \mathrm{~mm}$ thickness. The $100 \mathrm{x}, \mathrm{n}$.A. 1.3 oil immersion lens was focussed to the top of the chamber. Ten to twenty infection structures of each experiment were measured. The standard deviation is indicated in the figure.

\section{Results}

The infection structures of rust fungi (Fig. 1) are not easily detected with a microscope or stained in an infected leaf. Therefore, we used infection structures that were artificially induced on membranes (see Staples and Macko 1984).

Using such infection structures, WGA bound to the germ tubes and to the appressoria of Puccinia coronata avenae (Fig. 2) and Uromyces appendiculatus. In contrast to observations by Barraqueta-Egea and Schautz (1983), we were not able to measure a difference in fluorescence along the germ tube. Laminarinase (Fig. 3), exoglucanase and endoglucanase bound to the appressorium, to the substomatal vesicle and to the infection hyphae of the two rust fungi. We observed only faint binding of PHA to the substomatal vesicle of $U$. appendiculatus (Fig. 4).

Since the brightness of fluorescence is difficult to estimate objectively and depends partly on the type and quality of the microscope used, we used a microscope photometer to measure fluorescence intensity. Using standard procedures, we found (Fig. 5) that the fluorescence intensity of bound WGA was two to three times higher on the germ tubes and appressoria of $P$. coronata avenae than of $U$. appendiculatus. There was only very low fluorescence on the substomatal vesicle and the infection hypha of both rust fungi. Binding was easily reduced with chitin hydrolysate. GSA II and ConA bound in a typical pattern to all infectionstructures of both rust fungi with a faint fluorescence not easily estimated without the photometer. The fluorescence was significantly inhibited with $\mathrm{N}$-acetylglucosamine and $\alpha$-methylmannopyranoside respectively. Likewise PHA binding was indicated by a faint fluorescence. With $P$. coronata avenae, we could not inhibit this binding very well. But binding of PHA to the substomatal vesicle and 

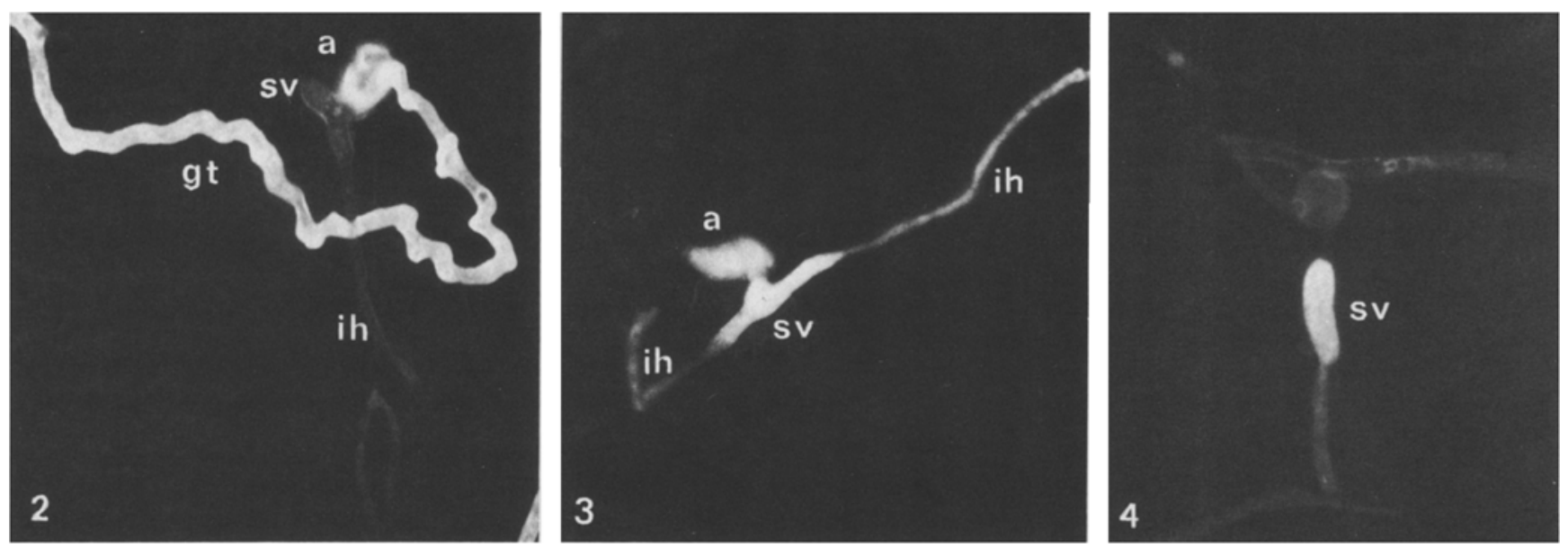

Fig. 2. Infection structures of Puccinia coronata, spread on a membrane after incubation with FITC-WGA. Germ tube gt and appressorium $a$ exhibit bright fluorescence. The substomatal vesicle $s v$ and the infection hypha ih show no fluorescence, $\times 350$

Fig. 3. Infection structures of Puccinia coronata after incubation with FITC-laminarinase, on a membrane. The germ tube shows no fluorescence. The appressorium a, the substomatal vesicle $s v$ and the two infection hyphae $i h$ exhibit a bright fluorescence, $\times 350$

Fig. 4. Infection structures of Uromyces appendiculatus after incubation with FITC-PHA, on a membrane. Some fluorescence on the substomatal vesicle $s v$ can be seen, $\times 350$

also to the infection hypha of $U$. appendiculatus could be inhibited with $\mathrm{N}$-acetylgalactosamine.

LTA bound quite faintly to the infection structures of both rust fungi. Since it was difficult to inhibit this binding, results were inconclusive. We did not detect any binding of RCA I and PNA.

The binding of the laminarinase was not measured since enzyme binding could not be inhibited with laminarin. The purified endo- $(1 \rightarrow 3)-\beta$-glucanase showed a clear binding to appressoria, substomatal vesicles and infection hyphae of both rust fungi. Binding to all structures was inhibited by laminarin. A similar result was obtained with exo-(1-3)- $\beta$ glucanase. This latter enzyme exhibited a significantly higher binding to the infection structures of $U$. appendiculatus than to those of $P$. coronata avenae.

Except for GSA II, the spores showed considerable fluorescence after incubation with the different lectins and enzymes that could not be inhibited by the inhibitory sugars to a great extent.

\section{Discussion}

Lectins have proved to be a very useful tool in surface studies of bacteria and fungi (Bauer 1981; Chaboud and Lalonde 1983; Hermanns and Ziegler 1984; Hinch and Clarke 1980; Kauss 1981). In these studies, the estimation of brightness of the emitted light was very difficult. Unfortunately, also the microscope photometer allows only relative measurements. However, after calibration with a reliable standard, it gives reproducible results. Under the assumption, that the surface of different parts of the two rust fungi have a comparable surface texture (Dickinson 1977), we could show differences in the number of binding sites. Unfortunately, we generally do not know very much about the number of binding sites of the different lectins and enzymes (Goldstein and Hayes 1978; Goldstein 1981). Also the molar ratio FITC/protein ranges in the case of ConA and exo- $\beta$-glucanase between 2.3 and 1.0 (Lange, unpublished). Therefore, our measurements give relative values only for every probe used and do not indicate relative values among different probes.

The hydrophobic uredospores of the two rust fungi used here bound most lectins and enzymes. Except for GSA II, we were not able to inhibit fluorescence of uredospores with carbohydrates to a great extent. This observation is in agreement with results of Young and Kauss (1982) who found that wall fragments of spores of Colletotrichum lindemuthianum bound to quite a number of different proteins. Also, many lectins tend to attach to hydrophobic surfaces (Ochoa et al. 1981).

The germ tube differentiates appressoria and subsequent infection structures only after a signal from the stoma under natural conditions (Staples and Macko 1984). Dickinson (1955) was the first to show that there is a difference between the "outer" and the "inner" hypha of the rust fungus. Heath and Heath (see: Littlefield and Heath 1979, pp 100-103) found that the germ tube wall is continuous with the outer layer of the appressorium and a new inner layer appears. This new layer later forms, at the bottom of the appressorium, the wall of the infection peg and then the substomatal vesicle and the infection hypha.

Our results indicate that the fungal surfaces change during infection in the following way:

1. The germ tubes of both rust fungi have chitin on their surface. Puccinia coronata has two times more binding sites for WGA than does Uromyces appendiculatus. $U$. appendiculatus also seems to have some $(1 \rightarrow 3)$ - $\beta$-glucans with the nonreducing terminal exposed at the surface since the exo- $(1 \rightarrow 3)-\beta$-D-glucanase binds to the nonreducing terminal of the glucan chain. Also, according to the cleaving specificity of this enzyme, there may be some $(1 \rightarrow 6)$ branching since it binds also adjacent to $(1 \rightarrow 6)$ - $\beta$-linkages (Nelson et al. 1969; Reese and Mandels 1959).

2. The substomatal vesicles and the infection hyphae of $U$. appendiculatus and $P$. coronata have not much chitin on their surface, but manly glucans. $U$. appendiculatus seems to have more nonreducing terminals of the $(1 \rightarrow 3)-\beta$-D-glucan 

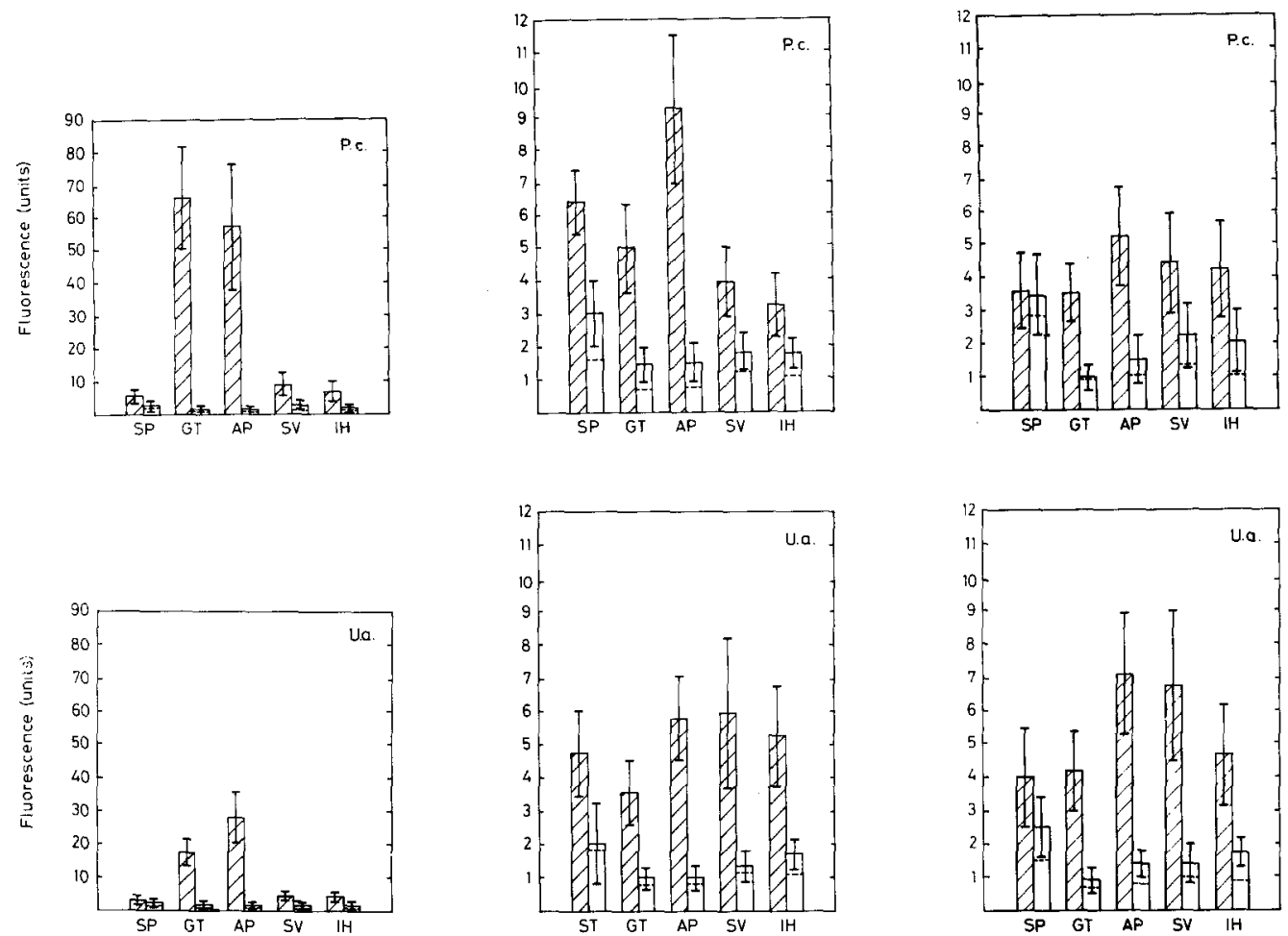

Triticum vulgaris lectin (WGA)

Griffonia simplicifolia lectin (GSA II)
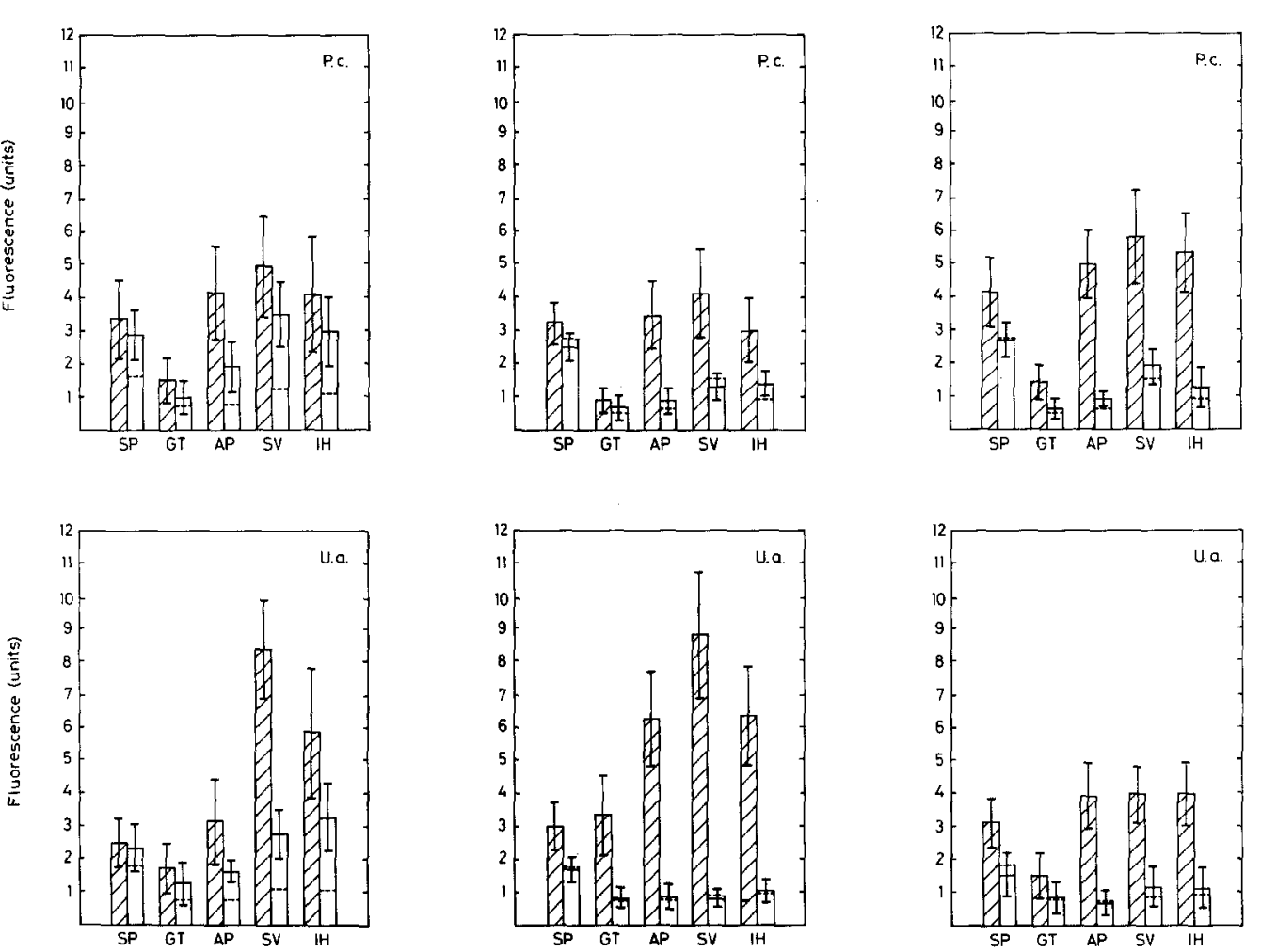

Phaseolus vulgaris lectin (PHA)

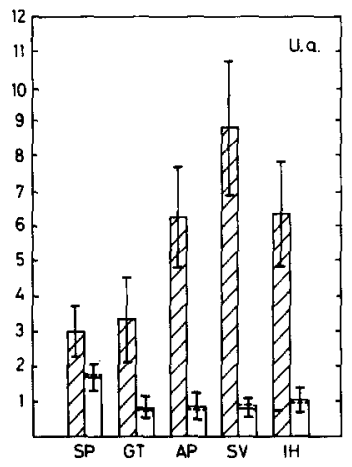

exo- $(1 \rightarrow 3)-\beta-D-g l u c a n a s e$

\section{Concanavalia ensiformis lectin (ConA)}

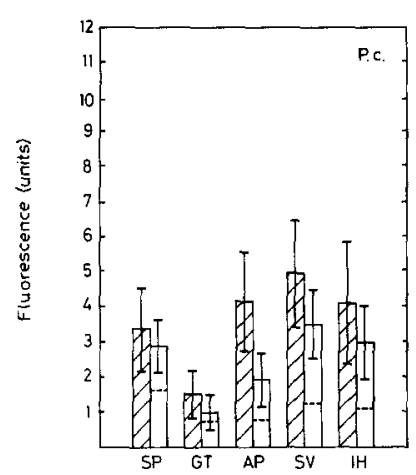

Fig. 5. Fluorescence intensity of the different enzymes and lectins on the uredospores $S P$, germ tubes $G T$, appressoria $A P$, substomatal vesicles $S V$ and infection hyphae $I H$ of Puccinia coronata P.c. and Uromyces appendiculatus $U . a .:$, buffer control: [], and after incubation with the lectin or enzyme, but including the inhibitory hapten $\square$ 
accessible to the exo- $(1 \rightarrow 3)-\beta-\mathrm{D}$-glucanase than $P$. coronata on its surface.

There is another important difference between the two rust fungi: PHA (a lectin from bean) binds to the substomatal vesicle of $U$. appendiculatus (a parasite of bean). This binding can be inhibited with $\mathrm{N}$-acetylgalactosamine. Although the specificity of this lectin is difficult to interprete (Goldstein and Hayes 1978; Ochoa et al. 1981), it may provide a site for a specific interaction between the fungus and its host.

3. The appressoria of both rust fungi unite the surface characteristics of the germ tube and the substomatal vesicle: All lectins and enzymes that bind to either of the latter structures bind to the appressorium in a pattern, typical for each rust.

4. The results with the other lectins indicate that there are some glucose or mannose (ConA), terminal N-acetylglucosamine (GSA II) and few fucose (LTA) residues, but no galactose (PNA, RCA I) residues on the surfaces of the infection structures of both rust fungi.

The aim of this study was not to find a "lectin" that specifically interacts between host and parasite, but to show that these very similar parasites have different surfaces and change these surfaces during the different processes of infection.

Acknowledgements. We are especially indebted to Dr. E. T. Reese for a generous gift of the exo- and endo-glucanase. We thank Prof. Dr. W. R. Bushnell and Prof. Dr. R. G. Kapooria for reading the manuscript and the Deutsche Forschungsgemeinschaft for a grant.

\section{References}

Albersheim P, Anderson-Prouty AJ (1975) Carbohydrates, proteins, cell surfaces, and the biochemistry of pathogens. Ann Rev Plant Physiol 26: $31-52$

Bauer WD (1981) Infection of legumes by Rhizobia. Ann Rev Plant Physiol 32:407-449

Barraqueta-Egea P, Schauz K (1983) The influence of phytolectins on spore germination of Tilletia caries, Puccinia graminis and Aspergillus flavus. Z Pflanzenkrankh Pflanzensch 90:488-495

Benjaminson M (1969) Conjugates of chitinase with FITC or lissamine rhodamine as specific stains for chitin in situ. Stain Technol 44:27-31

Chaboud A, Lalonde M (1983) Lectin binding on surfaces of Franckia strains. Can J Bot 61:2889-2897

Dickinson S (1955) Studies in the physiology of obligate parasitism: $V$. Further differences between the uredospore germ tubes and leaf hyphae of Puccinia triticina. Ann Bot NS 19:161-171

Dickinson S (1977) Studies in the physiology of obligate parasitism. $X$. Induction of responses to a thigmotropic stimulus. Phytopath Z 89:97-115

Goldstein IJ (1981) Plant derived lectins. In: Loewus FA, Ryan CA (eds) The phytochemistry of cell recognition and cell surface interactions. Plenum, New York, pp 25-35

Goldstein IJ, Hayes CE (1978) The lectins - carbohydrate binding proteins of plants and animals. Adv Carb Chem Biochem $35: 128-270$
Hankin L, Anagnostakis SL (1975) The use of solid media for detection of enzyme production by fungi. Mycologia 67:597607

Hermanns R, Ziegler E (1984) Localisation of $\alpha$-mannan in the hyphal wall of Phytophtora megasperma f. sp. glycinea and its possible relevance to the host-pathogen interaction of the fungus with soybeans (Glycine max). Phytopath Z 109:363-366 366

Hinch JM, Clarke AE (1980) Adhesion of fungal zoospores to root surface is mediated by carbohydrate determinants of root slime. Physiol Plant Path 16:303-308

Jongsma APM, Hijmans W, Ploem JS (1971) Quantitative immunofluorescence. Histochemie 25:329-343

Joppien S, Burger A, Reisener HJ (1972) Untersuchungen über den chemischen Aufbau von Sporen und Keimschlauchwänden der Uredosporen des Weizenrostes. Arch Mikrobiol 82:337-352

Kauss H (1981) Lectins and their physiological role in slime moulds and in higher plants. In: Tanner W, Loewus FH (eds) Plant carbohydrates, vol II, Encyclopedia of Plant Physiology, New Series. Springer, Heidelberg Berlin New York, pp 627-657

Kim WK, Rohringer R, Chong J (1982) Sugar and amino acid composition of macromolecular constituents released from walls of uredosporelings of Puccinia graminis tritici. Can J Plant Pathol 4:317-327

Littlefield L, Heath M (1979) Ultrastructure of rust fungi. Academic Press, New York, pp 100-103

Maheshwari R, Hildebrandt AC, Allen PJ (1967) Physical and chemical factors controlling the development of infection structures from uredospore germ tubes of rust fungi. Phytopathology 57: $855-862$

Mirelman D, Galun E, Sharon N, Lotan R (1975) Inhibition of fungal growth by wheat germ agglutinin. Nature $256: 414-416$

Nairn RC (1964) Fluorescent protein tracing. Livingstone, London

Nelson ThE, Johnson J, Jantzen E, Kirkwood S (1969) Action pattern and specificity of an exo- $\beta$ - $(1 \rightarrow 3)$-D-glucanase from basidiomycetes species QM 806. J Biol Chem 244:5972-5980

Ochoa JL, Sierra A, Cordoba F (1981) On the specificity and hydrophobicity of lectins. In: Bøg-Hansen TC (ed) Lectins. W. de Gruyter, Berlin, pp 73-80

Pistole TG (1981) Interaction of bacteria and fungi with lectins and lectin-like substances. Ann Rev Microbiol 35:85-112

Reese ET, Mandels M (1959) $\beta$-D-(1 $\rightarrow 3$ ) glucanases in fungi. Can $\mathrm{J}$ Microbiol 5:173-185

Staples RC, Macko V (1984) Germination of urediospores and differentiation of infection structures. In: Bushnell WR, Roelfs AT (eds) The cereal rusts, vol I. Academic Press Orlando, pp 255-289

Trocha P, Daly JM, Langenbach RJ (1974) Cell walls of germinating uredospores, I. Plant Physiol 53: 519-526

Trocha P, Daly JM (1974) Cell walls of germinating urediospores, II. Plant Physiol 53:527-532

Wimmer M (1984) Die Induktion von Infektionsstrukturen beim Haferkronenrost in künstlichen Systemen. Diplomarbeit, Univ. Konstanz

Wessels JG, Sietsma JH (1981) Fungal cell walls - a survey. In: Tanner W, Loewus FH (eds) Plant carbohydrates, vol II, Encyclopedia of Plant Physiology, New Series. Springer, Heidelberg Berlin New York, pp 353-385

Young DH, Kauss H (1982) Agglutination of mycelial cell wall fragments and spores of Colletotrichum lindemuthianum by plant extracts, and by various proteins. Physiol Plant Path 20:285297

Received August 2, 1984/Accepted October 11, 1984 